This item was submitted to Loughborough's Research Repository by the author.

Items in Figshare are protected by copyright, with all rights reserved, unless otherwise indicated.

\title{
Investigating the individual trust and school performance in semi-virtual collaboration groups
}

PLEASE CITE THE PUBLISHED VERSION

https://doi.org/10.1108/ITP-01-2016-0024

\section{PUBLISHER}

(C) Emerald Publishing Limited

\section{VERSION}

AM (Accepted Manuscript)

\section{PUBLISHER STATEMENT}

This work is made available according to the conditions of the Creative Commons Attribution-NonCommercialNoDerivatives 4.0 International (CC BY-NC-ND 4.0) licence. Full details of this licence are available at: https://creativecommons.org/licenses/by-nc-nd/4.0/

\section{LICENCE}

CC BY-NC-ND 4.0

\section{REPOSITORY RECORD}

Cheng, Xusen, Shixuan Fu, Yajing Han, and Alex Zarifis. 2019. "Investigating the Individual Trust and School Performance in Semi-virtual Collaboration Groups”. figshare. https://hdl.handle.net/2134/37519. 


\title{
Investigating the individual trust and school performance in semi-virtual collaboration groups
}

\author{
Xusen Cheng, Shixuan Fu and Yajing Han \\ School of Information Technology and Management, \\ University of International Business and Economics, Beijing, China, and \\ Alex Zarifis \\ University of Mannheim, Mannheim, Germany
}

\begin{abstract}
Purpose - The purpose of this paper is to investigate the relationship between individual trust of students in computer supported semi-virtual collaboration groups and student's performance in school.

Design/methodology/approach - Longitudinal questionnaires and interviews are conducted during the case study. By analyzing the data from the questionnaires and the grade earned by the students, the sample students are ranked with respect to the trust level and individual performance. Furthermore, the Wilcoxon signed-rank test is used to compare individual trust level and performance in the computer supported semivirtual collaborative environment.

Findings - The distribution of an individual's trust level is roughly consistent with the distribution of the individual's performance in the collaboration. Besides, the relationship between a student's trust level and the student's performance is positively correlated.

Research limitations/implications - This study integrates the issues of trust, school performance, and collaboration in an educational context. Furthermore, the conclusions drawn from this paper extend the literature of multiple disciplines including education, management, and psychology.

Practical implications - The conclusions could apply in the fields of education and management since the analysis revealed the relationship between an individual's trust level and their performance.

Originality/value - This study contributes to the field of trust and collaboration research with a link to trust development and performance. The study also provides an insight into how to successfully improve the performance of student semi-virtual collaboration groups.
\end{abstract}

Keywords Virtual teams, Education, Trust, Collaboration, Work performance

Paper type Research paper

\section{Introduction}

Due to the development of collaborative information technology (IT), a collaborative learning team is an effective format that has a wide range of applications, especially in higher education. As the main purpose of higher education is to cultivate the talent of the students and to improve their abilities, it is vital to make the optimal use of the collaborative learning method. Finding ways to improve the effectiveness, efficiency, and performance of each student involved in the collaborative teams has therefore become an important and challenging issue (Cheng, Li, Sun and Huang, 2016).

The concept of trust has been an important dimension of team collaboration within organizations (e.g. Colquitt et al., 2007; Bigley and Pearce, 1998; Jarvenpaa et al., 2004; Rousseau et al., 1998). Many scholars have conducted extensive research to explore whether there is a relationship between the level of trust and performance. Tomlinson et al. (2009) postulated trust congruence among integrative negotiators as a predictor of joint-behavioral outcomes. Hsu et al. (2007) studied the relationship between trust and expected outcomes. More recently, Chang and Lee (2013) demonstrated that trust serves as a learning facilitator affecting a students 
learning performance on Facebook, an online virtual community. In conclusion, the majority of existing research has shown that the trust level is one of the factors influencing performance. Despite this however, there are limited conclusions drawn about what the exact relationship is. Previous research in this area also suffers from the following limitations. Primarily, the methods used to measure both the trust levels and the performances are challenged. On the one hand, many of the studies were measured qualitatively, which brings a certain level of subjectivity to the research (Hanushek, 1997). However, in comparison, much of the research was conducted either in a traditional face-to-face context or in the purely virtual context rather than the most common semi-virtual environment (Hsu et al., 2007; Wilson et al., 2006; Piccoli and Ives, 2003). In addition, there is also a lack of literature in individual trust and performance focused in semi-virtual collaboration environments. Nonetheless, semi-virtual collaboration, with participants using computer support and meeting face to face, has currently become a popular method of collaboration (Cheng, Macaulay and Zarifis, 2013). It is therefore interesting to investigate the relationship between the trust level and the performance of individuals in semi-virtual collaboration teams over time. We propose the following two questions for our research:

$R Q 1$. Is there any relationship between the trust level and performance of the individuals involved in the student semi-virtual collaboration groups over time?

$R Q 2$. If a relationship exists, what is the relationship?

The overall structure of the study takes the form of six chapters, including this introductory section. Then, we begin with a literature review in Section 2, and an exploratory case study in Section 3. Following the case study, we will measure the trust level and the performance quantitatively and comprehensively. The Wilcoxon signed-rank test is used, and we will describe the relationship between the trust level and the performance of the individuals. Subsequently, we use the interview data to demonstrate the result qualitatively. We will then compare our research with the previous literature, concluding our theoretical contributions and practical implications. Finally, we note some limitations of this research and directions for future work.

\section{Literature review}

\subsection{Trust}

Trust is defined as the willingness of a party to be vulnerable to the actions of another party based on the expectation that the latter will perform a particular action important to the trustor irrespective of the ability to monitor or control the other party (Mayer et al., 1995). The trust level in teams is influenced by the communication medium (Jarvenpaa et al., 2004). The research of Iacono and Weisband (1997) also suggested that high levels of trust were maintained in teams that engaged in continuous and frequent interaction. Iacono and Weisband (1997) found that these high-trust teams were more efficient in moving through the phases of the project.

Trust is valued in all areas of business and industry, locally and globally, since it has been proven to be a powerful factor in determining the effectiveness of group collaboration (Child, 2001). Hsu et al. (2007) investigated the effect of trust on the process of knowledge sharing. From the research of Tomlinson et al. (2009), trust can be a predictor of the efficacy of the knowledge sharing process. Specifically, trust is a continuous topic of research and studies in education. Hooghe et al. (2012) have also drawn attention to the relationship between trust and education.

Many scholars have explored various types of trust approaching the subject from different perspectives, such as interpersonal trust (Paul and McDaniel, 2004; Jarvenpaa et al., 2004), interorganizational trust (Zaheer et al., 1998), system trust (Sarker et al., 2011), and individual trust (Nolan et al., 2007). They have also investigated trust within different 
timeframes, such as swift trust (Crisp and Jarvenpaa, 2013), and trust development over time (Wilson et al., 2006; Nolan et al., 2007; Cheng, Macaulay and Zarifis, 2013; Cheng, Yin, Azadegan and Kolfschoten, 2016).

Nolan et al. (2007) have deconstructed individual trust into six factors allowing them to evaluate trust development: risk (associated with providing information to unknown recipients and acting upon information received from them), benefit (an overall perception that involvement will provide individual gain), utility value (measured by high-quality information that can immediately be put into practice), interest (indicating an inherent interest in the system and the information available), effort (the effort exerted to acquire information), and power (an individual's ability to influence others by means of their superior knowledge and/or access to information). In order to investigate the development of individual trust, Nolan et al. (2007) presented an exploration of the trust level over three stages during the whole research period in business collaboration teams. The six individual trust factors are also further verified using an online student collaboration context through the work of Cheng and Macaulay (2014).

\subsection{Virtual collaboration}

A significant number of organizations, especially task-oriented groups, use collaborative work practices to help achieve success. Collaborative work practices are also common in a wide range of universities and colleges since the IT was used to support collaboration has undergone remarkable development (Cheng et al., 2016). Generally, there are three types of collaboration, which are: face-to-face, purely virtual, and semi-virtual (hybrid) collaboration (Griffith et al., 2003). Face-to-face collaboration is the most common form in traditional practice. Nowadays, the growing literatures on distance learning have shown that computer-mediated collaborative learning facilitates students' self-efficacy and social presence compared with the face-to face collaboration (Alvarez et al., 2011). Computermediated (purely virtual) collaboration primarily refers to the use of tools and technologies, such as electronic mail, computer conferencing, and online databases ( Jonassen et al., 1995). In addition, group support systems also have the potential to provide support to distributed teams and organizations. Thus, there is a growing body of literature that recognizes the importance of virtual collaborative learning (Sung and Hwang, 2013), and this form is also widely adopted by many educational and organizational practitioners.

Nevertheless, in the field of computer-mediated collaboration, the adoption of face-to-face interaction has been confirmed to be useful in virtual collaboration, and has also shown to improve trust in comparison to purely virtual collaboration (Fiol and O'Connor, 2005; Wilson et al., 2006; Weinel et al., 2011). In most universities, many lecturers not only use computer supported tools and platforms for student group tasks but also face-to-face meetings to supplement a students' virtual collaboration. Although some research has been carried out in the context of collaborative learning, and focused on the empirical investigations into the mediation effect of collaborative activities, such as students' perceptions, learning outcomes, etc. The associated empirical investigations into semi-virtual collaborative learning are still limited (Cheng and Macaulay, 2014; Roblyer et al., 2010).

In collaborative works, trust, as one of the social factors, has been validated to be helpful for explaining the perception of the students, thus influence the outcome of learning activities, such as school performance (Chang and Wong, 2010), collaboration satisfaction (Briggs et al., 2003), and personal achievement (Owston et al., 2013). Trust was deemed as the collaboration factor loading of the student attitude (Ku et al., 2013). In online collaborative learning, the learner-centered instructions were important for collaborative trust building from the perspective of cognition and affection (Tseng et al., 2015). But those who are critical of the use of online tools see online learning as anti-social, which inhibits the trust building process for the mechanical nature of online courses (Harney et al., 2012). Sometimes it is also challenging to build trust in the collaborative learning environment because 
the cohesiveness is difficult to build in virtual settings (Tseng and Yeh, 2013). However, in the blended course, students are able to receive knowledge and feedbacks from various sources, the flexibility of semi-virtual collaborative learning supplements the shortcomings of the two pure forms (Owston et al., 2013), and are more easier for trust building. Moreover, the in-depth discussion in face-to-face interactions and the convenience nature in online collaborations increase the potential of individual's cognitive assessment toward the other person's behavior, thus facilitate trust building and maintenance (Tseng and Yeh, 2013).

\subsection{Determinant of school performance}

In the university context, academic performance is typically the most important factor to evaluate collaborative learning outcomes. School performance can be regarded as the efficiency and effectiveness of the studying process. Three typical factors used to measure school performance are attendance, the grade, and in-class performance of the students (Duff et al., 2004; Gottfried, 2010; Lin et al., 2003). From these three dimensions, many scholars have investigated diversified factors that have an influence on school performance. Among these factors, trust, as an indicator of mutual relationships, stands out in the team collaborative practices.

At the meanwhile, due to the generalization of collaboration groups in universities and colleges, an increasing number of studies regard interpersonal relationships and trust as a critical determinant to a student's performance in school collaborative learning (Aubert and Kelsey, 2003). Besides, trust has also been shown to have a moderating effect upon the willingness to participate and thus improve performance (Chang and Wong, 2010). The individual level trust can be transformed into organizational performance through the reduction of negotiation cost (Zaheer et al., 1998). From the work of Pinjani and Palvia (2013), it was shown that trust is also associated knowledge sharing that eventually influence team efficiency and performance.

In view of the role of trust in collaborative environments, various methods were used to empirically evaluate the relationships between trust and performance. For example, Sarker et al. (2011) investigated trust and virtual team performance in different models using a social networking approach. Pinjani and Palvia (2013) also explored trust and performance using a model including IT, satisfaction, and efficiency together in a knowledge sharing domain with global teams. However, these investigations were mainly about a single data analysis method that lack of triangulation, and seldom were conducted in blended courses. Therefore, we aim to conduct a case study with quantitative and qualitative method to follow the relationships of trust and school performance in the context of semi-virtual collaborative learning.

Thus, according to the argument above, we propose:

H1. The individual trust affects the student's performance.

\section{Case study}

Research conducted using a case study is a frequent experimental method in qualitative research. However, the technique has been subject to much criticism, specifically whether the results are generalizable and whether replicating the logic improves generalizability (Claeyé and Jackson, 2011; Tsang and Kwan, 1999; Yin, 2009). Empirically, college students undertaking a group project in a partial virtual environment are typically highly engaged in interpersonal collaboration. Further, since it is easy to value the performance of the students, student case studies are frequently used as the sample for researchers testing or evaluating techniques and models in the field of collaboration research (Richards, 2009; Chiu et al., 2010).

In our longitudinal study, we sampled a total of 36 undergraduate students who were attending the same course at a Chinese university during a semester lasting approximately four months. Of the 36 students aged between 20 and 25 years, 21 are female students and 15 are male. The participators are all of normal intelligence and well-educated, but they are 
from different schools and have various majors. They are capable of conducting the case study following the collaboration process and the professors' facilitation. We divide them into seven groups randomly, where each group is composed of five or six students. All groups are assigned a project task to be completed using group collaboration. The project task is to create a business plan with the help of professional knowledge that they were learning from the course itself. They are able to collaborate either face to face or via the internet. In regards to face-to-face collaboration, they can deliver, share or even debate their ideas directly. For online collaboration, they are able to use Tencent QQ (a popular Chinese online chatting tool) and MSN, in addition to other online chatting tools. In class, the students collaborate using face-to-face communication directed by the facilitator (professor) and the learning process. After class, they are able to use the online collaboration methods on weekdays and face-to-face methods in their independent discussions at the weekends. On the whole, all groups are required to spend almost the same time communicating face to face as the time communicating online. From the pedagogical aspects of the course, students had more freedom to finish their collaborative learning tasks with the help of the computer-mediated tools, the flexibility of the blended course makes students to be more active in collaborative activities, the travel time and expenses are reduced in semi-virtual forms, the convenience are good for students' final grades (Owston et al., 2013). Moreover, in blended courses, students' engagement is not only measured in the physical classroom, but also in the online learning communities. As engagement is a source of school performance (Duff et al., 2004), high level of engagement offered by the semi-virtual form eventually are beneficial for students' final achievements. We measured students' performance from both the online and offline channels. So their final grades are the combination of many aspects, which incorporates face-to-face meetings and online discussions.

In the collaboration process design, we have referred to Kolfschoten et al. (2007) to build guidelines for designing the collaboration process. We have suggested the students perform tasks such as brainstorming, categorizing, and voting when they collaborate. During this time, the students are available to collaborate face to face or through the internet using tools such as Power Meeting, Tencent QQ, and Kanbox. The students themselves arranged the collaboration work; however, they were required to complete within the project deadline. On the one hand, with regard to the face-to-face collaboration, the students can deliver, share, or even debate their ideas directly. In addition, the students are also permitted to use the advanced information technologies that they may prefer, for example, social networking websites, microblogs, online chatting tools, and even mobile phone applications. The online collaboration process guidance also serves to ensure students' online engagement.

In this study, we have chosen Nolan et al.'s (2007) six trust factors as measurement instruments. As we aim to explore the relationship between the individual trust level and the students' performance, we plan to measure the trust level and the performance of each individual. Since the refinement of skills in one area often leads to the neglect of skills in another domain (Edge, 2013), in the current context, the assumption is that achievement relates to academic performance. Although academic performance may be influenced by factors such as the samples basic intellectual and emotional capacities as well as their socio-cultural backgrounds (Gathercole and Pickering, 2000), the students are encouraged to use the knowledge they have learned from the course.

To measure an individual's performance, all students were required to complete a questionnaire three times during the project period to value their trust level from the six trust factors we selected (Cheng, Nolan and Macaulay, 2013). We also conducted interviews with each of the students. In order to measure the performance of the students we focused on three points: regular performance (class participation, attendance, and homework), midterm performance (the midterm presentation and the midterm project results), and the final performance (the final presentation and the final project result) (Figure 1). 
Figure 1.

The relationship between individual trust and an individual's performance
Figure 2.

Research process
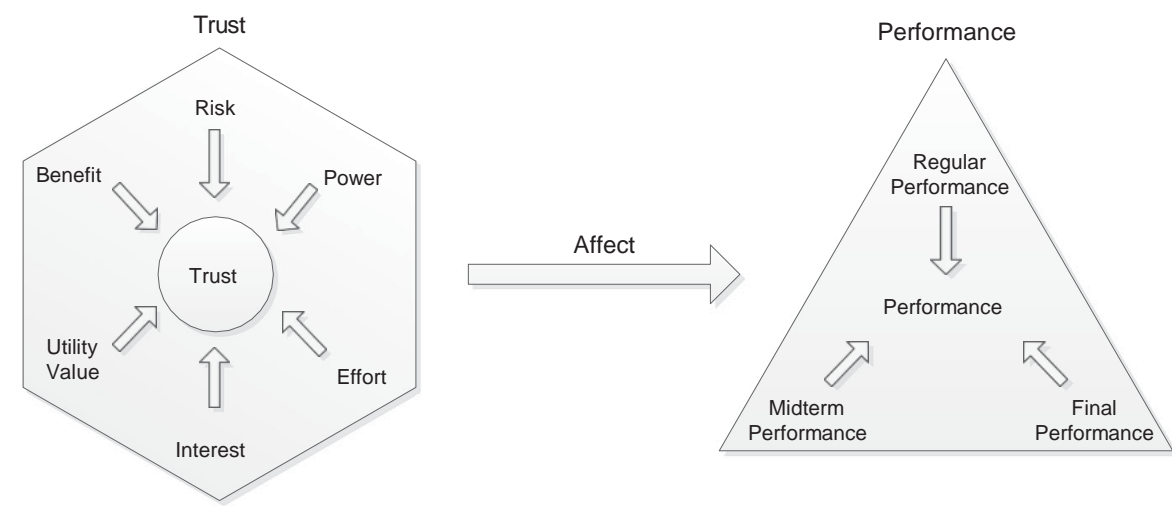

Upon completion of the quantifying of the data collected in the research, we were able to rank the 36 students from the aspect of trust and performance. We questioned the sample students using the Trust Evaluation Survey (Cheng, Nolan and Macaulay, 2013) in order to measure the individual trust level at each stage (Cheng, Nolan and Macaulay, 2013). A participant was required to respond to the statements using a scale of 1-5, where 1 represented the strongest disagreement and 5 represented the strongest agreement. An individual's scores for each statement were aggregated to arrive at a single score for the factor, which was then averaged. In addition, we valued an individual's school performance as the weighted average of regular performance, midterm performance, and final performance. Through comparison of the individual trust level in different surveys with the respective school performance, we arrived at the relationship between the trust level and school performance. Furthermore, we were also able to determine the development of the relationship as time progresses. Figure 2 illustrates our research process.

As for the interview protocols, the interview guides had three general sections: respondents' background and their attitude toward semi-virtual collaborative learning; the perceptions of the overall individual trust level; and finally, respondents' feedback to the blended course regarding the performance in different stages. At the end of each interview, we asked informants to share any other information they felt was relevant.

\section{Data analysis and results}

In order to analyze our data we adopted both a quantitative and qualitative method. We valued the trust level from the six aspects, that is, risk, effort, benefits, power, utility value, and interest (Nolan et al., 2007). Cheng, Macaulay and Zarifis (2013) also raised the notion of an ideal value of the six factors with the help of a trust spider diagram (Figure 3).

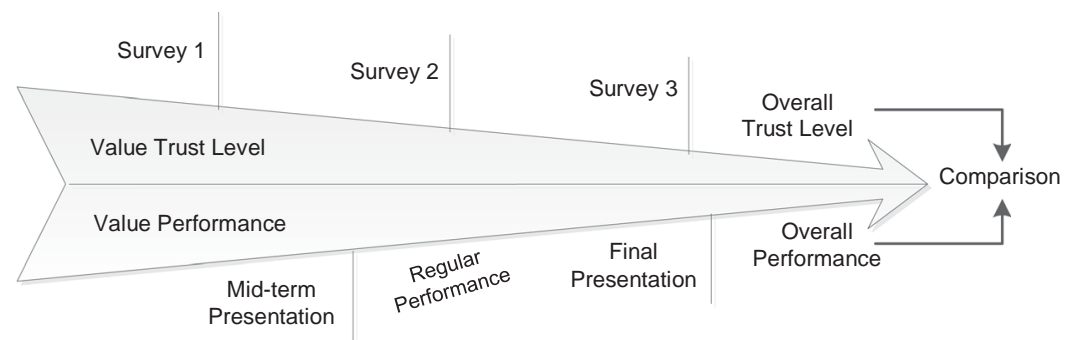




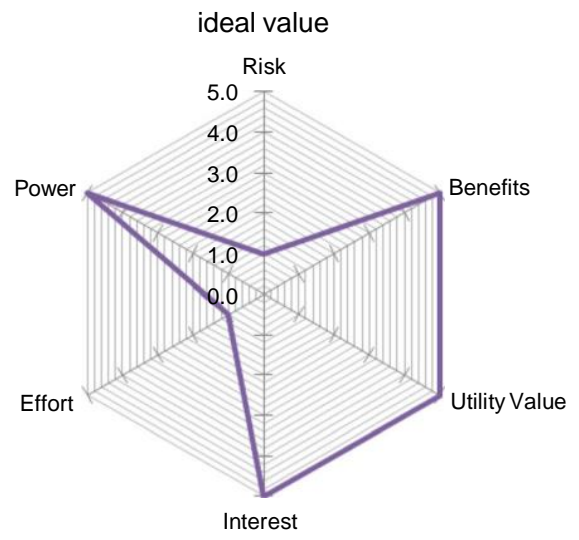

The ideal value for each of the six factors is 1, 1, 5, 5, 5, and 5, respectively (Cheng, Nolan and Macaulay, 2013).

We first calculated the students' real value in the six trust factors during three surveys for all 36 sample students. We then introduced the concept of Difference, which shows the total gap between the ideal value and the real value of the six factors, and used this to measure the trust level. The greater the value of the Difference is, the lower the trust level. The Difference is calculated as follows:

$$
\text { Difference }=\sum_{j=1}^{6}\left|A_{j}-I_{j}\right|,
$$

where $j$ is the serial number of the six factors, $A_{j}$ is the average real value of the factor, $j$ for each group, and $I_{j}$ is the ideal value of the factor $j$.

By ranking the Difference in ascending order, we are able to derive the trust level order of the 36 students in different surveys (Table I).

From the results of the three surveys, we find that there is no uniformed trust development trend over time. The Difference of each individual in three stages is generally steady. This suggests that the semi-virtual collaborative environment helps maintain trust. Compared with previous literatures that trust started lower in virtual collaborative teams but increased to levels comparable to those in face-to-face teams over time (Wilson et al., 2006), this result also validate the advantages of semi-virtual collaboration from the perspective of trust building and trust maintenance.

In regards to academic performance, a grade falling below the predicted obtainable grade is easily measured. That is, achievement falling below what would be forecast from our most informed and accurate prediction, based on a team of predictor variables (Lozier and Mills, 2011). The students' performance can be measured is as follows:

$$
\text { Performance }=0.3 \times \text { Grade }_{\text {regular }}+0.3 \times \text { Grade }_{\text {midterm }}+0: 4 \times \text { Grade }_{\text {final }} ;
$$

where Grade $_{\text {regular }}$ is the grade of regular performance given by the teacher, Grade midterm $_{\text {is the }}$ grade of the midterm performance given by the teacher, and Gradefinal is the grade of the final performance given by the teacher. In all cases, the maximum score 100 and minimum score 0 . Performance is the total grade of each individual.

The weighting values used on each individual part of the performance $(0.3,0.3$, and 0.4$)$ were determined with the aid of teachers and the class itself. Therefore, they are able to
Figure3.

The ideal value of the six factors of trust 


\begin{tabular}{|c|c|c|c|c|c|c|}
\hline \multirow[b]{2}{*}{ Student ID } & \multicolumn{2}{|c|}{ Survey 1} & \multicolumn{2}{|c|}{ Survey 2} & \multicolumn{2}{|c|}{ Survey 3} \\
\hline & Difference & Trust rank & Difference & Trust rank & Difference & Trust rank \\
\hline No. 1 & 10.88 & 33 & 9.85 & 29 & 10.52 & 33 \\
\hline No. 2 & 11.20 & 35 & 6.20 & 3 & 7.21 & 10 \\
\hline No. 3 & 8.79 & 22 & 8.69 & 21 & 13.07 & 36 \\
\hline No. 4 & 8.46 & 18 & 8.15 & 15 & 7.07 & 8 \\
\hline No. 5 & 7.90 & 13 & 6.00 & 2 & 6.00 & 5 \\
\hline No. 6 & 8.89 & 23 & 8.90 & 24 & 8.88 & 23 \\
\hline No. 7 & 9.90 & 29 & 9.82 & 28 & 9.98 & 28 \\
\hline No. 8 & 8.43 & 16 & 8.40 & 16 & 8.47 & 19 \\
\hline No. 9 & 9.66 & 28 & 10.33 & 32 & 10.40 & 32 \\
\hline No. 10 & 10.07 & 31 & 11.33 & 35 & 9.41 & 27 \\
\hline No. 11 & 5.68 & 2 & 6.23 & 4 & 5.13 & 2 \\
\hline No. 12 & 7.75 & 11 & 8.74 & 23 & 7.34 & 11 \\
\hline No. 13 & 8.45 & 17 & 8.45 & 18 & 8.46 & 18 \\
\hline No. 14 & 7.65 & 10 & 7.65 & 10 & 8.30 & 17 \\
\hline No. 15 & 6.70 & 4 & 7.86 & 12 & 5.54 & 3 \\
\hline No. 16 & 9.32 & 27 & 8.50 & 19 & 8.50 & 20 \\
\hline No. 17 & 8.51 & 20 & 11.07 & 34 & 11.07 & 34 \\
\hline No. 18 & 7.40 & 7 & 9.30 & 26 & 9.30 & 26 \\
\hline No. 19 & 8.15 & 15 & 9.61 & 27 & 7.56 & 13 \\
\hline No. 20 & 7.64 & 9 & 7.93 & 13 & 7.95 & 16 \\
\hline No. 21 & 8.90 & 24 & 6.94 & 6 & 6.94 & 7 \\
\hline No. 22 & 11.40 & 36 & 10.77 & 33 & 12.03 & 35 \\
\hline No. 23 & 6.45 & 3 & 8.01 & 14 & 7.15 & 9 \\
\hline No. 24 & 9.11 & 26 & 9.90 & 30 & 10.17 & 31 \\
\hline No. 25 & 10.05 & 30 & 10.01 & 31 & 10.10 & 30 \\
\hline No. 26 & 8.50 & 19 & 6.60 & 5 & 5.64 & 4 \\
\hline No. 27 & 9.10 & 25 & 9.26 & 25 & 8.94 & 24 \\
\hline No. 28 & 8.05 & 14 & 7.60 & 9 & 7.60 & 14 \\
\hline No. 29 & 7.05 & 5 & 8.42 & 17 & 6.80 & 6 \\
\hline No. 30 & 10.90 & 34 & 8.70 & 22 & 8.70 & 22 \\
\hline No. 31 & 7.47 & 8 & 7.47 & 8 & 10.01 & 29 \\
\hline No. 32 & 8.78 & 21 & 8.52 & 20 & 8.55 & 21 \\
\hline No. 33 & 7.78 & 12 & 7.78 & 11 & 7.78 & 15 \\
\hline No. 34 & 5.02 & 1 & 5.10 & 1 & 4.79 & 1 \\
\hline No. 35 & 10.39 & 32 & 11.53 & 36 & 9.25 & 25 \\
\hline No. 36 & 7.19 & 6 & 7.44 & 7 & 7.44 & 12 \\
\hline
\end{tabular}

measure the students' performance comprehensively. We were able to calculate each student's corresponding rank of performance (Table II) using the same student Ids as in Table I.

Furthermore, we employed a rank-sum test to explore whether a relationship exists between the trust level and the performance of the 36 students. Since there are 36 samples in the research $(n \leqslant 50)$, we employed the Wilcoxon signed-rank test to compare the results. For $H O$, we hypothesized that the distribution of the two groups of data were roughly consistent, while $H \mathrm{H}$ is defined as not equal to $\mathrm{HO}$.

Test standard $\mathrm{a}=0: 05$

We were able to develop a Rank matrix of all sample data from the three surveys (Table III) with the help of SPSS. Specifically, concerning the comparison between the trust level from survey 1 and the school performance, the matrix demonstrated that there are 17 negative ranks, that is, there are 17 students for whom the rank of trust is larger than the rank of 


\begin{tabular}{|c|c|c|c|c|c|}
\hline $\begin{array}{l}\text { Student } \\
\text { ID }\end{array}$ & $\begin{array}{l}\text { Performance } \\
\text { rank }\end{array}$ & $\begin{array}{l}\text { Grade of school } \\
\text { performance }\end{array}$ & $\begin{array}{l}\text { Student } \\
\text { ID }\end{array}$ & $\begin{array}{l}\text { Performance } \\
\text { rank }\end{array}$ & $\begin{array}{l}\text { Grade of school } \\
\text { performance }\end{array}$ \\
\hline No. 1 & 33 & 82 & No. 19 & 15 & 91 \\
\hline No. 2 & 6 & 92 & No. 20 & 20 & 90 \\
\hline No. 3 & 32 & 84 & No. 21 & 13 & 92 \\
\hline No. 4 & 7 & 92 & No. 22 & 25 & 88 \\
\hline No. 5 & 36 & 70 & No. 23 & 18 & 90 \\
\hline No. 6 & 3 & 94 & No. 24 & 21 & 89 \\
\hline No. 7 & 16 & 91 & No. 25 & 10 & 92 \\
\hline No. 8 & 2 & 94 & No. 26 & 27 & 86 \\
\hline No. 9 & 17 & 91 & No. 27 & 24 & 88 \\
\hline No. 10 & 9 & 92 & No. 28 & 29 & 86 \\
\hline No. 11 & 31 & 85 & No. 29 & 1 & 97 \\
\hline No. 12 & 22 & 89 & No. 30 & 12 & 92 \\
\hline No. 13 & 11 & 92 & No. 31 & 8 & 92 \\
\hline No. 14 & 23 & 88 & No. 32 & 35 & 74 \\
\hline No. 15 & 5 & 93 & No. 33 & 28 & 86 \\
\hline No. 16 & 34 & 80 & No. 34 & 4 & 94 \\
\hline No. 17 & 14 & 92 & No. 35 & 26 & 88 \\
\hline No. 18 & 19 & 90 & No. 36 & 30 & 85 \\
\hline
\end{tabular}

Table II.

Rank of each student's performance

\begin{tabular}{|c|c|c|c|}
\hline & $n$ & Mean rank & Sum of ranks \\
\hline \multicolumn{4}{|l|}{ Ranks - Survey 1} \\
\hline \multicolumn{4}{|c|}{ Rank of trust - rank of performance } \\
\hline Negative ranks & $17^{\mathrm{a}}$ & 18.88 & 321 \\
\hline Positive ranks & $17^{\mathrm{b}}$ & 16.12 & 274 \\
\hline Ties & $2^{\mathrm{c}}$ & & \\
\hline Total & 36 & & \\
\hline \multicolumn{4}{|l|}{ Ranks - Survey 2} \\
\hline \multicolumn{4}{|c|}{ Rank of trust - rank of performance } \\
\hline Negative ranks & $16^{\mathrm{a}}$ & 19.03 & 304.5 \\
\hline Positive ranks & $19^{\mathrm{b}}$ & 17.13 & 325.5 \\
\hline Ties & $1^{\mathrm{c}}$ & & \\
\hline Total & 36 & & \\
\hline \multicolumn{4}{|c|}{ Ranks - Survey 3} \\
\hline \multicolumn{4}{|c|}{ Rank of trust - rank of performance } \\
\hline Negative ranks & $16^{\mathrm{a}}$ & 16.79 & 285.5 \\
\hline Positive ranks & $19^{\mathrm{b}}$ & 18.21 & 309.5 \\
\hline Ties & $1^{\mathrm{c}}$ & & \\
\hline Total & 36 & & \\
\hline
\end{tabular}

Notes: ${ }^{a}$ Rank of trustorank of performance; ${ }^{b}$ rank of trust Wrank of performance; ${ }^{c}$ rank of trust 4 rank of performance

Table III. Rank matrix

performance. Similarly, there are 17 positive ranks and two ties. The sum of negative ranks and positive ranks were 321 and 274, respectively. For the data from survey 2, we are able to conclude that there are 16 negative ranks, 19 positive ranks, and only 1 tie. For the data from survey 3 , we found that there are 16 negative ranks, 19 positive ranks, and 1 tie.

We arrived at the conclusion shown in Table IV using the Wilcoxon signed-rank test. From the results, we found that the possibility that $H O$ is correct $\left(P^{1 / 4} 0.668,0.863,0.837\right)$ in 
three surveys is larger than $\alpha(0.05)$. Therefore, the $H O$ is reasonable in all the three stages. This confirms that the trust level of the individual student did impact the student's performance.

Therefore, in regards to our first research question, the first conclusion we arrived at from the research is as follows.

Conclusion 1: there is indeed a relationship between the trust level and the performance of the individuals involved in the collaboration groups.

Since the number of students with positive ranks $(17,19,19)$ is greater than the number with negative ranks $(17,16,16)$ in all three stages, we can conclude that the relationship between the students' trust level and their performance is positive. That is, the higher the student's trust level, the better the student performed.

We also interviewed all students in respect to their trust level with the other team members. We transcribed the interview and extracted some of the students' responses. Through analyzing the transcript manually, we were able to divide each student's perception of their own trust level into three groups, that is, positive, neutral, and negative. Furthermore, Table V compares the rank of performance and the student's perception of their own trust level to determine if a relationship exists between the trust level and performance of each student involved.

According to the interview data and the results of the Wilcoxon signed-rank test, we found that the students who performed better usually had a higher level of trust. Therefore, our second conclusion is as follows.

Conclusion 2: a student's level of trust with the collaborators is positively correlated to their performance.

The results of this study draw important implications for research and theories around the relationship between a student's individual trust level to collaborators and the individual's performance. We concluded that the distribution of the students' trust level was consistent with the distribution of the students' performance through use of the Wilcoxon signed-rank test. After comparing the data further, we also determined that the relationship is positively correlated. We also interviewed some of the students during the research. The conversations supported our research conclusions: many of the sample students said that their performance was easily improved when the individuals trusted each other.

\section{Contribution and implications}

\subsection{Theoretical contribution}

This study integrates the issues of trust, school performance, and collaboration in an educational context. The current results make several theoretical contributions compared with previous works. First, the semi-virtual collaboration is seen as an important way to maintain trust and facilitate performance. We contribute to the research in the area of semi-virtual

Table IV.

Results of the Wilcoxon signed-rank test
Trust - performance

$\begin{array}{lc}\text { Test } \text { statistics }^{\mathrm{b}} \text { - Survey } 1 & -0.402^{\mathrm{a}} \\ Z & 0.688 \\ \text { Asymp. Sig. (2-tailed) } & -0.172^{\mathrm{a}} \\ \text { Test statistics }{ }^{\mathrm{b}}-\text { Survey } 2 & 0.863 \\ Z & \\ \text { Asymp. Sig. (2-tailed) } & -0.205^{\mathrm{a}} \\ \text { Test statistics }{ }^{\mathrm{b}} \text { - Survey } 3 & 0.837 \\ Z & \end{array}$




\begin{tabular}{|c|c|c|c|}
\hline Num. & $\begin{array}{l}\text { Rank of } \\
\text { performance }\end{array}$ & Attitudes & Interview comments example \\
\hline No. 11 & 10 & Neutral & I am not sure about how much I trust the others \\
\hline No. 8 & 23 & Negative & I don't have enough trust in my mates \\
\hline No. 10 & 31 & Negative & My trust level decreased sharply after I found they were irresponsible \\
\hline No. 12 & 27 & Negative & $\begin{array}{l}\text { In fact, I didn't trust my team members because they always missed } \\
\text { the deadline }\end{array}$ \\
\hline No. 17 & 3 & Positive & As the time goes on, I trust them more and more \\
\hline No. 27 & 24 & Negative & The students didn't pay enough attention, and I trust them less and less \\
\hline No. 18 & 9 & Positive & $\begin{array}{l}\text { I trusted my mates because we are punctual of time, even in the channel } \\
\text { of e-collaboration }\end{array}$ \\
\hline No. 21 & 28 & Negative & I don't know why, but I just don't trust my team members \\
\hline No. 6 & 33 & Neutral & Sometimes I trust my mates, but sometimes not \\
\hline No. 14 & 14 & Neutral & Since we didn't know each other before, I didn't trust the others at first \\
\hline No. 5 & 2 & Positive & I definitely relied on my partners \\
\hline No. 9 & 32 & Negative & $\begin{array}{l}\text { We are likely to share ideas with each other at first, but it is maintained } \\
\text { only for a short time in f } 2 \mathrm{f}\end{array}$ \\
\hline No. 1 & 17 & Neutral & I only trusted my team members when they contributed a lot to our team \\
\hline No. 24 & 25 & Negative & $\begin{array}{l}\text { In general, we could hardly have a smooth collaboration, and we didn't } \\
\text { trust each other well }\end{array}$ \\
\hline No. 25 & 35 & Negative & Since we didn't trust each other, we didn't do a good job \\
\hline No. 16 & 26 & Neutral & I just trusted my team members sometimes \\
\hline No. 33 & 16 & Neutral & $\begin{array}{l}\text { At first, I wasn't confident in my team members, but then, the situation } \\
\text { has improved }\end{array}$ \\
\hline No. 36 & 4 & Positive & In most instances, I trust my team members \\
\hline
\end{tabular}

Table V.

Interview transcript and performance rank

collaboration by investigating the value of six trust factors. Specifically, we examined three general indicators through stages to evaluate the outcome of performance. In general, the results are in line with the existing research (Zaheer et al., 1998; Chang and Lee, 2013) that trust serves as a learning facilitator that affects a student's learning performance.

Second, unlike previous studies that focused purely on virtual or face-to-face groups, such as Jarvenpaa et al.'s (2004) global virtual teams, Wilson et al.'s (2006) face-to-face preferences, and Piccoli and Ives' (2003) online teams, we instead chose to focus on the semivirtual collaboration environment since this context is more consistent with the reality of higher education. Our research serves as one of the first that incorporate trust and performance in semi-virtual team collaboration. This paper contributes to the previous works by investigating the trust building mechanism and the associated performance in semi-virtual collaborative environment. The positive relationship between trust and performance were validated in our new context.

Moreover, we also adopted multiple methods (including, spider diagram, longitudinal trust development survey, in-depth interview, and the Wilcoxon signed-rank test) in this study, improving the prior research using one or two methods in the case study (Cheng, Macaulay and Zarifis, 2013). In comparison to prior research on individual trust development (Cheng and Macaulay, 2014; Cheng, Macaulay and Zarifis, 2013; Cheng, Nolan and Macaulay, 2013), we have found that trust maintain steady in our blended courses. Additionally, we measured individual trust development relating to school performance in a semi-virtual collaboration environment, removing the limitations of previous research (Cheng, Nolan and Macaulay, 2013). Compared with previous research on blended course, the flexible nature of semi-virtual environments is again proven to be helpful for trust maintenance (Owston et al., 2013; Harney et al., 2012).

In regards to the issue of school performance, we have also developed an equation for accurate measurement. Formula (2) provides a persuasive method to measure each student's 
performance comprehensively, in contrast to previous research that focuses solely on the final grade (Felder et al., 2012). In order to measure academic performance, we have also improved upon the conventional methods where failing achievement was determined by falling below what would be forecast from our most informed and accurate prediction, based on a team of predictor variables (Lozier and Mills, 2011; Betts et al., 2009).

Taking these key findings together, our study reveals an effective way of teaching in terms of pedagogical aspects. The results are important contributions to our theoretical understanding of how trust and performance are correlated in the existing semi-virtual investigations. Compared with research conducted in purely face-to-face settings (Alvarez et al., 2011), the improvement of flexibility helps maintain the level of trust in the blended course. While in comparison to research in purely virtual environment (Piccoli and Ives, 2003), the semi-virtual form in this study also provides the opportunity for team members to meet each other, which facilitate the familiarity among team members, and finally helps with the performance.

\subsection{Practical implication}

The conclusions drawn from our research may be applicable in the fields of education and management since the analysis revealed the relationship between an individual's trust level and their performance.

In the majority of existing colleges, collaborative learning groups have become the most common manifestation of the collaborative learning methodology. Therefore, it has been imperative for the school authority to improve the performance of students that are involved in collaborative groups. The conclusion drawn from our research indicates a student's performance can be improved by increasing trust within the group, and improved individual performance may even elevate the performance of the group and the college as a whole. The blended course enables students to engage in the class through computer supported learning practice and offers opportunity for students to study conveniently, thus facilitate trust building and trust maintenance. From the pedagogical aspect of the blended course, the flexible nature of blended course also provide students more freedom to conduct collaborative discussions, and thus is encouraged to be widely adopted by educational practitioners. Therefore, to improve the trust level, the school authority can establish peer-relation programs to increase familiarity among students, an outcome that can increase the trust level. Our research also shows that schools should give equal attention to the students' trust education, such as launching more social activities and courses for the students to increase familiarity and promote better relationships. Since online collaboration is effective (Koh and Lim, 2012), the teachers should also motivate the students to adopt online techniques efficiently. This research will also give clues to the blended learning education environment for half classroom and half online learning settings.

In the field of management there are also some useful implications. First, managers should not only focus on the task itself but should also give due care to the collaboration culture of the teams by promoting individual trust and interpersonal relationships. Second, like the school authority, managers should also establish internal programs to strengthen friendship among the employees in order to improve performance. Third, according to the research of Qiu and McDougall (2013), managers should carefully monitor team composition to maximize effectiveness.

\section{Conclusion and future work}

\section{Conclusion}

In relation to the questions we proposed at the beginning, we can draw two primary conclusions from the research, which shows the relationship between a student's trust level and their performance in a collaborative group. The first conclusion is that the distribution of an individual's trust level is roughly consistent with the distribution of the individual's 
performance in the collaboration. That is, a student's trust level, in respect to all aspects (risk, benefit, interest, utility value, effort, and power), affects their performance in the collaboration. The second conclusion shows that the relationship between a student's trust level and the student's performance is positively correlated. That is, the more the individuals trust each other, the better they perform, and vice versa. In a word, trust, a factor that is important in multiple disciplines, also plays a significant role in the field of education, especially in the performance of students engaging in team collaboration.

\section{Limitations and future work}

However, the research does suffer from some limitations, which mainly appear in the data we collected and the method we adopted. First, with respect to the data, we found that the quantity of samples we investigated were not sufficient enough; the subset was too small to represent all students in the world. Second, the subjectivity of the questionnaire and the grade granted by the teachers may add some uncertainty to the data. Third, the research was not conducted repeatedly; multiple case studies would provide further insight. There are also some limitations in the method we adopted in the research. The efficacy of the formulas we used to measure the trust level and performance may vary when used in other contexts. Lastly, the influence of demographic factors on the trust level was omitted.

In order to deliver better results in the future, we are in the process of optimizing the research both in theory and in practice. Therefore, in the future, we will attempt to diminish the limitations and errors through the following techniques. First, we will conduct additional student samples to validate our findings, and repeat the research in other contexts, such as global teams, cross-cultural teams, and teams from other countries where we may arrive at different conclusions. Second, by continuous practice and testing, we aim to improve the formulas and methodology we adopted in this research. With these improvements, we can arrive at more accurate conclusions and draw more useful implications. Moreover, we will also expand the samples from the student communities to other contexts, such as businesses, to explore whether the trust level has such a significant influence on the group performance in various research settings.

Future work is also encouraged to consider the relationships of trust development and performance evolvement as the time passes by, especially in the context of semi-virtual collaboration. In terms of the blended course, whether trust building mechanism is different with other research settings, whether trust is more and more correlated with performance and whether team performance is triggered by the improvement of trust are all worth investigating in the future. Furthermore, as the perceived trust may have mutual influences within a group, it is also an interesting topic to investigate the influence of group trust to performance. Last but maybe not the least, we are also interested in conducting an experiment study to compare trust and performance in semi-virtual environment and the purely virtual context.

\section{References}

Alvarez, C., Brown, C. and Nussbaum, M. (2011), "Comparative study of netbooks and tablet PCs for fostering face-to-face collaborative learning", Computers in Human Behavior, Vol. 27 No. 2, pp. 834-844.

Aubert, B.A. and Kelsey, B.L. (2003), "Further understanding of trust and performance in virtual teams", Small Group Research, Vol. 34 No. 5, pp. 575-618.

Betts, L.R., Rotenberg, K.J. and Trueman, M. (2009), "The early childhood generalized trust belief scale”,

Early Childhood Research Quarterly, Vol. 24 No. 2, pp. 175-185.

Bigley, G.A. and Pearce, J.L. (1998), "Straining for shared meaning in organization science: problems of trust and distrust", Academy of Management Review, Vol. 23 No. 3, pp. 405-421.

Briggs, R.O., De Vreede, G.J. and Nunamaker, J.F. (2003), "Collaboration engineering with thinkletss to pursue sustained success with group support systems", Journal of Management Information Systems, Vol. 19 No. 4, pp. 31-64.

Chang, H.H. and Wong, K.H. (2010), "Adoption of e-procurement and participation of e-marketplace on firm performance: trust as a moderator”, Information \& Management, Vol. 47 No. 5, pp. 262-270.

Chang, W.-L. and Lee, C.-Y. (2013), "Trust as a learning facilitator that affects students' learning performance in the Facebook community: an investigation in a business planning writing course", Computers \& Education, Vol. 62, pp. 320-327. 
Cheng, X. and Macaulay, L. (2014), "Exploring individual trust factors in computer mediated group collaboration: a case study approach", Group Decision and Negotiation, Vol. 23 No. 3, pp. 533-560.

Cheng, X., Fu, S. and Druckenmiller, D. (2016), "Trust development in globally distributed collaboration: a case of US and Chinese mixed teams", Journal of Management Information Systems, Vol. 33 No. 4, pp. 978-1007.

Cheng, X., Macaulay, L. and Zarifis, A. (2013), "Modeling individual trust development in computer mediated collaboration: a comparison of approaches", Computers in Human Behavior, Vol. 29 No. 4, pp. 1733-1741.

Cheng, X., Nolan, T. and Macaulay, L. (2013), "Don't give up the community: a viewpoint of trust development in online collaboration”, Information Technology \& People, Vol. 26 No. 3, pp. 298-318.

Cheng, X., Li, Y., Sun, J. and Huang, J. (2016), “Application of a novel collaboration engineering method for learning design: a case study”, British Journal of Educational Technology, Vol. 47 No. 4, pp. 803 818.

Cheng, X., Yin, G.P., Azadegan, A. and Kolfschoten, G.L. (2016), "Trust evolvement in hybrid team collaboration: a longitudinal case study", Group Decision and Negotiation, Vol. 25 No. 2, pp. 267-288.

Child, J. (2001), "Trust - the fundamental bond in global collaboration", Organizational Dynamics, Vol. 29 No. 4, pp. 274-288.

Chiu, C.H., Yang, H.Y., Liang, T.H. and Chen, H.P. (2010), "Elementary students' participation style in synchronous online communication and collaboration", Behaviour and Information Technology, Vol. 29 No. 6, pp. 571-586.

Claeyé, F. and Jackson, T. (2011), "Project delivery in HIV/AIDS and TB in Southern Africa: the cross-cultural management imperative", Journal of Health Organization and Management, Vol. 25 No. 4, pp. 469-486.

Colquitt, J.A., Scott, B.A. and LePine, J.A. (2007), "Trust, trustworthiness, and trust propensity: a metaanalytic test of their unique relationships with risk taking and job performance", Journal of Applied Psychology, Vol. 92 No. 4, pp. 909-927.

Crisp, C.B. and Jarvenpaa, S.L. (2013), "Swift trust in global virtual teams", Journal of Personnel Psychology, Vol. 12 No. 1, pp. 45-56.

Duff, A., Boyle, E., Dunleavy, K. and Ferguson, J. (2004), "The relationship between personality, approach to learning and academic performance", Personality and Individual Differences, Vol. 36 No. 8, pp. 1907-1920.

Edge, K. (2013), "Rethinking knowledge management: strategies for enhancing district-level teacher and leader tacit knowledge sharing", Leadership and Policy in Schools, Vol. 12 No. 3, pp. 227-255.

Felder, P., Griebler, R., Samdal, O., King, M.A., Freeman, J. and Duer, W. (2012), "Does the school performance variable used in the international health behavior in school-aged children (HBSC) study reflect students' school grades?", Journal of School Health, Vol. 82 No. 9, pp. 404-409.

Fiol, C.M. and O'Connor, E.J. (2005), "Identification in face-to-face, hybrid, and pure virtual teams: untangling the contradictions", Organization Science, Vol. 16 No. 1, pp. 19-32.

Gathercole, S.E. and Pickering, S.J. (2000), "Working memory deficits in children with low achievements in the national curriculum at 7 years of age", British Journal of Educational Psychology, Vol. 70 No. 2, pp. 177-194.

Gottfried, M.A. (2010), "Evaluating the relationship between student attendance and achievement in urban elementary and middle schools an instrumental variables approach", American Educational Research Journal, Vol. 47 No. 2, pp. 434-465.

Griffith, T.L., Sawyer, J.E. and Neale, M.A. (2003), "Virtualness and knowledge in teams: managing the

love triangle of organizations, individuals, and information technology", MIS Quarterly, Vol. 27

No. 3, pp. 265-287.

Hanushek, E.A. (1997), “Assessing the effects of school resources on student performance: an update”, Educational Evaluation and Policy Analysis, Vol. 19 No. 5, pp. 141-164.

Harney, O., Hogan, M.J. and Broome, B.J. (2012), "Collaborative learning: the effects of trust and open and closed dynamics on consensus and efficacy", Social Psychology of Education, Vol. 15 No. 4, pp. 517532.

Hooghe, M., Marien, S. and de Vroome, T. (2012), "The cognitive basis of trust: the relation between education, cognitive ability, and generalized and political trust", Intelligence, Vol. 40 No. 6, pp. 604-613.

Hsu, M.H., Ju, T.L., Yen, C.H. and Chang, C.M. (2007), "Knowledge sharing behavior in virtual communities: the relationship between trust, self-efficacy, and outcome expectations", International Journal of Human-Computer Studies, Vol. 65 No. 2, pp. 153-169.

Iacono, C.S. and Weisband, S. (1997), "Developing trust in virtual team", Proceedings of the Thirtieth 
Hawaii International Conference on System Sciences, Vol. 2, January, pp. 412-420.

Jarvenpaa, S.L., Shaw, T.R. and Staples, D.S. (2004), "Toward contextualized theories of trust: the role of trust in global virtual teams", Information Systems Research, Vol. 15 No. 3, pp. 250-267.

Jonassen, D., Davidson, M., Collins, M., Campbell, J. and Haag, B.B. (1995), "Constructivism and computer-mediated communication in distance education", American Journal of Distance Education, Vol. 9 No. 2, pp. 7-26.

Koh, E. and Lim, J. (2012), "Using online collaboration applications for group assignments: the interplay between design and human characteristics", Computers \& Education, Vol. 59 No. 2, pp. 481-496.

Kolfschoten, G.L., den Hengst-Bruggeling, M. and de Vreede, G.J. (2007), "Issues in the design of facilitated collaboration processes", Group Decision and Negotiation, Vol. 16 No. 4, pp. 347-361.

$\mathrm{Ku}, \mathrm{H} . Y$. . Tseng, H.W. and Akarasriworn, C. (2013), "Collaboration factors, teamwork satisfaction, and student attitudes toward online collaborative learning", Computers in Human Behavior, Vol. 29 No. 3, pp. 922-929.

Lin, R.S., Fung, B.K., Hsiao, J.K. and Lo, H.F. (2003), "Relationship between academic scores and performance on national qualified examination for registered professional nurses (NQEX-RPN)", Nurse Education Today, Vol. 23 No. 7, pp. 492-497.

Lozier, J.D. and Mills, N.J. (2011), "Predicting the potential invasive range of light brown apple moth (Epiphyas postvittana) using biologically informed and correlative species distribution models", Biological Invasions, Vol. 13 No. 10, pp. 2409-2421.

Mayer, R.C., Davis, J.H. and Schoorman, F.D. (1995), "An integrative model of organizational trust", Academy of Management Review, Vol. 20 No. 3, pp. 709-734.

Nolan, T., Brizland, R. and Macaulay, L. (2007), "Individual trust and development of online business communities", Information Technology \& People, Vol. 20 No. 1, pp. 53-71.

Owston, R., York, D. and Murtha, S. (2013), "Student perceptions and achievement in a university blended learning strategic initiative", Internet and Higher Education, Vol. 18, pp. 38-46.

Paul, D.L. and McDaniel, R.R. Jr (2004), "A field study of the effect of interpersonal trust on virtual collaborative relationship performance", MIS Quarterly, Vol. 28 No. 2, pp. 183-227.

Piccoli, G. and Ives, B. (2003), "Trust and the unintended effects of behavior control in virtual teams", MIS Quarterly, Vol. 27 No. 3, pp. 365-395.

Pinjani, P. and Palvia, P. (2013), "Trust and knowledge sharing in diverse global virtual teams", Information \& Management, Vol. 50 No. 4, pp. 144-153.

Qiu, M. and McDougall, D. (2013), "Foster strengths and circumvent weaknesses: advantages and disadvantages of online versus face-to-face subgroup discourse", Computers \& Education, Vol. 67, pp. 1-11.

Richards, D. (2009), "Designing project-based courses with a focus on group formation and assessment", ACM Transactions on Computing Education, Vol. 9 No. 1, pp. 2-40.

Roblyer, M.D., McDaniel, M., Webb, M., Herman, J. and Witty, J.V. (2010), "Findings on Facebook in higher education: a comparison of college faculty and student uses and perceptions of social networking sites", The Internet and Higher Education, Vol. 13 No. 3, pp. 134-140.

Rousseau, D.M., Sitkin, S.B., Burt, R.S. and Camerer, C. (1998), "Not so different after all: a crossdiscipline view of trust", Academy of Management Review, Vol. 23 No. 3, pp. 393-404.

Sarker, S., Ahuja, M., Sarker, S. and Kirkeby, S. (2011), "The role of communication and trust in global virtual teams: a social network perspective", Journal of Management Information Systems, Vol. 28 No. 1, pp. 273-310.

Sung, H.Y. and Hwang, G.J. (2013), "A collaborative game-based learning approach to improving students' learning performance in science courses", Computers \& Education, Vol. 63, pp. 43-51.

Tomlinson, E.C., Dineen, B.R. and Lewicki, R.J. (2009), "Trust congruence among integrative negotiators as a predictor of joint-behavioral outcomes", International Journal of Conflict Management, Vol. 20 No. 2, pp. 173-187.

Tsang, E.W.K. and Kwan, K.M. (1999), "Replication and theory development in organization science: a critical realist perspective", Academy of Management Review, Vol. 34 No. 4, pp. 759-780.

Tseng, H., Morris, B. and Tang, Y. (2015), "The importance of teamwork trust, social presence, and cognitive presence in an online collaborative learning environment", Proceedings of the International Conference in Society for Information Technology \& Teacher Education, Vol. 2015 No. 1, pp. 538-541.

Tseng, H.W. and Yeh, H.T. (2013), "Team members' perceptions of online teamwork learning experiences and building teamwork trust: a qualitative study", Computers \& Education, Vol. 63, pp. 1-9.

Weinel, M., Bannert, M., Zumbach, J., Hoppe, H.U. and Malzahn, N. (2011), “A closer look on social presence as a causing factor in computer-mediated collaboration", Computers in Human Behavior, Vol. 27 No. 1, pp. 513-521. 
Wilson, J.M., Straus, S.G. and McEvily, B. (2006), "All in due time: the development of trust in computer- mediated and face-to-face teams", Organizational Behavior and Human Decision Processes, Vol. 99 No. 1, pp. 16-33.

Yin, R.K. (2009), Case Study Research: Design and Methods, Sage, Thousand Oaks, CA.

Zaheer, A., McEvily, B. and Perrone, V. (1998), "Does trust matter? Exploring the effects of interorganizational and interpersonal trust on performance", Organization Science, Vol. 9 No. 2, pp. 141-159. 


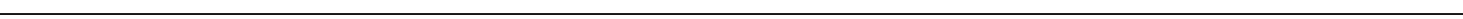

